\title{
Investigação qualitativa psicanaliticamente informada: Contributos teórico-metodológicos
}

\author{
Sandra Roberto', Filipa Falcão Rosado', Orlando Cruz Santos', Luís \\ Martins Pote $^{1}$ e Teresa Santos Neves ${ }^{1}$
}

\author{
1Sociedade Portuguesa de Psicanálise, Portugal | sandragasroberto@gmail.com; \\ filipa.rosado@gmail.com; santorlando@gmail.com; luismartinspote@gmail.com; \\ teresasantosneves@sapo.pt | https://orcid.org/0000-0002-9871-2713; https://orcid.org/0000- \\ 0002-7623-3746; https://orcid.org/0000-0000-0000-0000; https://orcid.org/0000-0000-0000- \\ 0000; https://orcid.org/0000-0001-7959-6043
}

Resumo: O presente artigo propõe uma reflexão teórico-metodológica sobre a investigação qualitativa psicanaliticamente informada. Pretende-se descrever a conceptualização de um dispositivo metodológico que recorre à ontologia e epistemologia psicanalítica, isto é, que parte de uma concepção de sujeito de investigação não "transparente", no sentido de não se dar a conhecer diretamente a si mesmo e aos outros. É, por isso, necessário promover meios (dispositivos) que facilitem o acesso ao sujeito, permitindo captar as dimensões explícitas de significação, mas também as dimensões pré-conscientes e inconscientes. Tendo por base estes princípios, foi desenvolvido um estudo conceptual sobre a contratransferência em psicanalistas utilizando as entrevistas de livre associação (FANI) como instrumento. O referido estudo é usado no artigo para explicitar a problematização teórico-metodológica do uso deste tipo de investigação qualitativa. A análise das entrevistas realizada pelo grupo de investigação no estudo conceptual serve de exemplo para explicitar as particularidades do dispositivo utilizado. Este dispositivo tem por base a dinâmica criada no grupo de investigação e a forma como emergem as linhas interpretativas das dimensões subjetivas inconscientes do entrevistado relativamente aos temas em estudo. Partindo de uma teorização sobre o trabalho do pensamento, destacamos três processos que permitem sustentar o procedimento adotado para a análise das entrevistas: capacidade negativa, trabalho de sonho alfa e facto selecionado.

Palavras-chave: Investigação Psicanalítica; Entrevistas de Livre Associação (FANI); Capacidade Negativa; Trabalho de Sonho Alfa; Facto Selecionado.

\section{Psychoanalytic Informed Qualitative Research: Theoretical Methodological Contributions}

Abstract The present article advances a theoretical and methodological reflection on psychoanalytic informed qualitative research. The goal is to describe the conceptualisation of a methodological device coherent with the ontological and epistemological assumptions of psychoanalysis. In other words, the device is based on the concept of a "non-transparent" research subject, who does not make his nature known to either himself or others. Therefore, the need arises for the development of devices which provide access to the subject, in order to grasp not just the explicit dimensions of signification, but also their pre-conscious and unconscious counterparts. A conceptual research was conducted on countertransference among psychoanalysts, resorting to free association narrative interviews (FANI). This study is covered in the article, so as to illustrate the identification of theoretical and methodological problems related to the usage of this type of qualitative research. An analysis of the interviews conducted by the research group, for the conceptual research, is used as an example, to illustrate the specific features of the employed device. The device is based on the dynamics created within the group and on the emergence of interpretative lines of the unconscious subjective dimensions of the interviewee, as they relate to the topics under analysis. Starting from a theoretical framework on thought work, we highlight three processes supporting the procedure used for analysing the interviews: negative capability, alpha dream work and selected fact.

Keywords: Research in Psychoanalysis; Free Association Narrative Interview (FANI); Negative Capability; Alpha Dream Work; Selected Fact. 


\section{Introdução}

A metodologia qualitativa de investigação tem vindo a ser utilizada na psicanálise de forma mais consistente nas últimas décadas (Stamenova \& Hinshelwood, 2018). Complementarmente, a investigação qualitativa tem recorrido à ontologia e à epistemologia psicanalítica para ampliar a compreensão dos fenómenos em estudo (Cartwright, 2004; Frosh \& Young, 2008; Hollway, 2004, 2008; Hollway \& Jefferson, 2008, 2013; Kvale, 2003). Neste sentido, o presente artigo propõe uma reflexão teóricometodológica sobre a investigação qualitativa psicanaliticamente informada. A partir de um estudo, ainda em curso, sobre o uso do conceito de contratransferência em psicanalistas, descrevemos a conceptualização de um dispositivo metodológico, psicanaliticamente informado (Holmes, 2019; Hollway, 2016; Hollway \& Jefferson, 2013). Este modelo, coerente com as premissas fundamentais da psicanálise, foi desenvolvido pelo nosso grupo de investigação e a nossa aprendizagem com a experiência de utilização deste dispositivo será objecto de análise.

Este modelo, de um ponto de vista ontológico, parte de uma concepção complexa do psiquismo humano, pressupondo duas ideias fundamentais. A primeira, refere-se à relação dialética e conflictual entre consciente/inconsciente implicando um sujeito dividido e defendido (Freud 1900/1953, 1916/1963). Esta perspectiva opõe-se à ideia quase implícita, noutros paradigmas, de que os sujeitos seriam "transparentes", totalmente cognoscíveis, para si mesmos e para aqueles com os quais comunicam, nomeadamente, para os investigadores (Hollway \& Jefferson, 2013). A segunda, refere-se ao modo de comunicação inconsciente assente num processo de identificação projectiva, através do qual a vivência afetiva do sujeito é projectada no outro que, por meio da identificação, a experiencia (Bion 1962, Hollway, 2016). Assim, na psicanálise a ideia da existência de significados latentes pressupõe um modo específico de pensar os indivíduos, que enfatiza os afectos, os conflictos dinâmicos e os processos intersubjectivos inconscientes.

Do ponto de vista epistemológico, o conhecimento do sujeito dividido e defendido requer um dispositivo específico que facilite o acesso aos significados latentes, inconscientes. Esse dispositivo assenta no binómio associação livre/atenção flutuante (Freud, 1900/1953, 1916/1963) que facilita uma expressão menos defendida do sujeito e uma recepção da sua comunicação (modo de escuta psicanalítico) também mais livre e aberta aos aspectos desconhecidos, defendidos, conflictuais, permitindo assim captar as dimensões explícitas de significação, mas também as dimensões pré-conscientes e inconscientes. Mais, o processo de conhecimento, entendido a partir dos aspectos relacionais e intersubjectivos, reconhece e privilegia também a experiência subjectiva consciente e inconsciente do investigador (Hollway, 2016). Estes princípios são vertidos nas opções metodológicas, traduzindo-se na escolha de métodos adequados à especificidade do objecto de estudo, numa articulação coerente entre princípios ontológicos, epistemológicos e metodológicos (Hollway, 2016).

Não sendo o propósito deste artigo dar conta da componente empírica da investigação conceptual sobre a contratransferência, contextualizamos brevemente o propósito da mesma para, em seguida, nos debruçarmos sobre os passos da nossa construção metodológica e a forma como foi sendo implementado, experienciado e reflectido no grupo de investigação.

\section{Uma investigação conceptual sobre a contratransferência}

A investigação em curso teve como objectivo problematizar e clarificar o campo de significação e uso da contratransferência, enquanto conceito e instrumento, no trabalho psicanalítico. Este conceito ilustra a constante interligação entre a teoria e a prática em psicanálise, tendo sofrido inúmeras modificações desde a sua formulação inicial em Freud (1910/1961). 
Assim, foi desenvolvido um projecto de investigação psicanaliticamente informado que visou aprofundar as metodologias associadas à investigação conceptual (Dreher, 2000), procurando problematizar o conceito, explorar a polissemia e heterogeneidade do seu uso, bem como as tensões entre o uso explícito e implícito do conceito para os psicanalistas na sua prática clínica.

A investigação conceptual em psicanálise define-se pelo seu objecto de estudo, isto é, os conceitos psicanalíticos que procuram apreender teoricamente os fenómenos clínicos (Dreher, 2000). Os conceitos psicanalíticos são polissémicos, têm significados explícitos, refletidos nas formulações da teoria, mas a prática clínica revela que os analistas tendem a atribuir significados subjectivos, resultantes de múltiplas influências a que o analista está sujeito (e.g., análise pessoal, supervisão, personalidade do analista). A investigação conceptual caracteriza-se pela análise sistemática dos significados, dos usos explícitos e implícitos dos conceitos, a sua origem, modificação e evolução tendo em conta os contextos clínicos e extra-clínicos (Sandler, Dreher \& Drews, 1991).

Neste contexto, a investigação realizada teve como ponto de partida as seguintes questões de investigação: 1) Quais as facetas implícitas do uso do conceito de contratransferência reveladas na prática clínica pelos/as psicanalistas?; 1.1) Qual a relação entre estes significados implícitos e as facetas explícitas do uso do conceito?; 2) Como é que o conceito de contratransferência vai sendo transformado ao longo da prática clínica?; 2.1) Qual a influência dos modelos teóricos e teórico-clínicos na compreensão e uso da contratransferência? 2.2) Qual o papel da formação formal e informal dos/das psicanalistas A presente investigação foi delineada, e tem sido conduzida, por cinco investigadores com formação e prática clínica psicanalítica, tendo igualmente experiência prévia na condução de investigação qualitativa psicanaliticamente informada.

\subsection{Procedimentos da Realização da Entrevista}

Num primeiro momento da nossa investigação, procedemos à análise sistemática da literatura sobre o conceito de contratransferência, assinalando a sua origem, os pontos de viragem e as perspectivas contemporâneas. Num segundo tempo, foram realizadas entrevistas individuais a um total de 6 psicanalistas, para aceder ao uso implícito do conceito. Os participantes foram selecionados por conveniência, através de um convite à participação no estudo endereçado ao universo de psicanalistas de uma Sociedade de Psicanálise, após o projecto de investigação ter sido submetido e aprovado pela Comissão de Ética da mesma.

Cada participante foi informado sobre o objectivo do estudo e foram garantidos a confidencialidade da sua participação e o anonimato no tratamento dos dados recolhidos. Os participantes foram também informados que todas as etapas da investigação respeitam os Códigos de Ética da Ordem dos Psicólogos Portugueses e da Sociedade Portuguesa de Psicanálise. Cada participante assinou um documento de consentimento informado.

Os participantes foram entrevistados por um dos elementos do grupo de investigação, uma única vez, que utilizou como instrumento de recolha de dados a Entrevista Narrativa de Associação Livre, desenvolvida por Hollway e Jefferson (2008, 2013). Este instrumento permite solicitar narrativas cujo conteúdo pode ser analisado nas suas dimensões implícitas, permitindo uma compreensão aprofundada dos significados subjectivos atribuídos pelos entrevistados aos temas propostos. Na presente investigação, a entrevista foi iniciada com uma questão aberta sobre a contratransferência. Seguidamente, foi explorada a experiência do analista relativamente ao fenómeno contratransferencial a partir do convite à partilha de relatos de casos da sua prática clínica. Por fim, foram colocadas questões em torno da influência do percurso formativo do entrevistado no desenvolvimento do uso clínico da contratransferência. Depois das entrevistas, o entrevistador, seguindo a metodologia descrita por Hollway e Jefferson (2013), tomava "notas de campo reflexivas" nas quais descrevia a sua experiência subjectiva do encontro. As entrevistas foram gravadas em registo áudio, e posteriormente transcritas. 


\subsection{Procedimentos de Análise da Entrevista}

A análise interpretativa das entrevistas e anotações foi realizada em quatro momentos distintos. No primeiro momento, a transcrição da entrevista foi lida pelo entrevistador e o grupo procurou escutar em atenção flutuante, implicando uma postura de abertura, expectativa vazia e insaturação. As impressões e hipóteses interpretativas foram emergindo em associação livre num processo de trabalho de sonho alfa e foram sendo anotadas por um membro do grupo. Assim, os factos selecionados emergiram naturalmente a partir do contacto com os dados. Pretendeu-se, assim, que espontânea e gradualmente pudessem emergir linhas compreensivas sobre o fenómeno da contratransferência, nas suas dimensões explícitas e implícitas. As categorias compreensivas de análise não foram, desta forma, previamente estabelecidas e impostas ao material. Seguidamente, foi realizada a leitura das notas de campo do entrevistador, confrontando-as com as primeiras hipóteses interpretativas. Depois procedeu-se a uma análise sistemática das notas da leitura das entrevistas procurando pôr em evidência os núcleos temáticos transversais que se destacaram. Finalmente procedeu-se ao confronto entre significados implícitos e explícitos clarificando, explorando e problematizando a sua articulação com a literatura.

\subsection{Contratransferência Erótica: Um Exemplo dos Procedimentos Metodológicos Psicanaliticamente Informados}

Pretendemos destacar da experiência de análise das entrevistas a forma como a dinâmica criada no grupo forneceu um dispositivo interpretativo desse mesmo material e, consequentemente, uma compreensão da subjetividade do entrevistado relativamente aos temas em estudo. Partimos da dinâmica estabelecida no grupo, a propósito da contratransferência erótica, enquanto tema introduzido por um dos entrevistados, para ilustrar os procedimentos psicanaliticamente informados alicerçados em conceitos significativos da psicanálise.

$\mathrm{Na}$ entrevista com a analista $\mathrm{A}$, a entrevistadora num determinado momento solicitou à psicanalista que the falasse sobre a contratransferência num caso clínico em análise. Em resposta a esse pedido, a analista, com alguns anos de experiência em psicanálise, referiu a propósito de um caso clínico de adulto:

"... percebi que houve uma parte importante do nosso trabalho em que eu estava de facto a vê-lo como um bebé, a infantilizá-lo, e não estava a fazer, a permitir que a parte mais madura da personalidade dele também cooperasse mais com o nosso trabalho e, portanto, o trabalho também progredisse, de outra forma, não é?

"Mas o facto é que ele era um homem e eu era uma mulher e fui-me dando conta que eu o ouvia como um, ah, um menino... Portanto eu estava, eventualmente eu estaria a dessexualizá-lo, não é ..."

"E é um exemplo de contratransferência durante muito tempo muito inconsciente, não é, e como estava a ser um obstáculo, e como depois de compreendida pode, pode ajudar, não é?"

A postura do grupo em associação livre durante a leitura da parte da entrevista acima descrita fez emergir uma dinâmica particular entre os elementos do grupo. Após um período de silêncio foram identificados os seguintes momentos de interação que transcrevemos abaixo:

Investigador 1 - A contratransferência nesta analista é percebida como um obstáculo

Investigador 2 - Fala-se da sexualidade ...

Investigador 3 - A sexualidade na contratransferência torna-a mais difícil de ser vivida e analisada internamente 
Investigador 4 - $O$ trabalho com os adultos é diferente do trabalho analítico com as crianças

Investigador 5 - Lembrei-me do texto do Ferenczi "Confusão de línguas". Esta confusão da linguagem dos adultos e das crianças

Neste ponto, seguiu-se no grupo uma longa discussão sobre a proposta de vários autores (Ferenczi, Amaral Dias e Laplanche), acerca da erotização das relações no processo de análise e a contransferência vivida pelos analistas.

No segundo momento, a análise das notas da discussão em grupo dá conta que a dinâmica estabelecida no grupo à volta da discussão teórica aparentemente muito valiosa pela riqueza intelectual dos argumentos, remetia para um processo defensivo pela dificuldade em verbalizar e articular a dimensão erotizada presente na relação de transferência-contratransferência. Ainda neste segundo momento, revelou-se uma dinâmica importante da entrevista, onde a contratransferência erótica foi identificada e nomeada pelo entrevistado, mas não foi um tema desenvolvido. Do mesmo modo, reinstalou-se no grupo o mesmo processo, em que se nomeou o fenómeno da contratransferência erótica, mas foi, seguidamente, silenciado através do recurso à intelectualização, evocando autores e teorias, evitando a emergência dos afectos e significados subjectivos.

\section{Discussão Teórica sobre o Procedimento}

A partir da conceptualização de Bion $(1959,1962,1970)$ sobre o trabalho do pensamento, extraímos três processos que permitem sustentar o procedimento adoptado para a análise das entrevistas: capacidade negativa, trabalho de sonho alfa e facto selecionado.

\subsection{Capacidade Negativa}

No primeiro contacto com a transcrição da entrevista o grupo de investigadores adoptou uma escuta que se aproxima da atenção flutuante do analista na clínica psicanalítica. Este conceito remete para o tipo de escuta do analista que não privilegia qualquer elemento do discurso do paciente e que deixa funcionar livremente a sua actividade inconsciente, suspendendo as motivações que habitualmente dirigem a sua atenção (Laplanche \& Pontalis, 1967)

A atenção flutuante pressupõe aquilo que Bion (1970) designou por capacidade negativa. Num primeiro momento da análise das entrevistas, os conteúdos não tinham uma forma definida na mente dos elementos do grupo e somente mais tarde vieram a configurar-se como formulação de uma hipótese interpretativa, pelo que foi necessário suportar a incerteza.

O conceito de capacidade negativa refere-se a um estado mental capaz de tolerar a ignorância, a incerteza, o mistério e a dúvida, sem a tentativa ansiosa de chegar a uma compreensão, ou sem uma obrigação de chegar ao facto (Bion, 1970). A capacidade de tolerar o não saber amplia a disponibilidade de contacto com o inconsciente. O autor refere que, no contexto clínico, o analista precisa de esperar o tempo necessário para que a compreensão dos processos inconscientes do paciente se desvele. Este tempo não pode ser determinado à priori e nem pode ser apressado. É o tempo de imersão na experiência emocional vivida entre paciente e analista até que o seu impacto possa começar a ser reconhecido, figurado, representado e compreendido.

O período de escuta do grupo e o silêncio que se seguiu à leitura do trecho foi o tempo em que o grupo permaneceu em estado de incerteza e de tolerância à "ignorância", sem tentativas de chegar a uma compreensão imediata ou à priori, aguardando o tempo necessário para que os conteúdos da entrevista fossem "digeridos" pela mente dos investigadores, para que a compreensão viesse a acontecer. 


\subsection{Trabalho de Sonho Alfa}

As intervenções dos elementos do grupo ocorreram em associação livre, como primeira tentativa de reconhecer e representar o impacto do que foi escutado. Permitindo que a associação livre fluísse, o grupo mergulhou numa discussão teórica. Podemos olhar para esta sequência como se de um sonho se tratasse: perante a evocação, pela entrevistada, da contratransferência erótica, os elementos do grupo visitaram as suas bibliotecas privadas e muniram-se de autores como se recorressem a armaduras, defendendo-se da inquietação provocada pelo trecho escutado. Imersos no sonho, como o sonhador, não se dão conta que estão a sonhar.

À semelhança da mente do analista que pode "sonhar" o material clínico do paciente, também o grupo fez uso desta função, recorrendo ao que Bion (1959) designou por trabalho em sonho alfa. Este conceito refere-se à aprendizagem através da experiência. Trata-se de uma função primordial do psiquismo que consiste em, permanentemente, de forma inconsciente, transformar a experiência emocional em pictogramas que são os elementos base do processo de figuração, simbolização e representação. Este processo que se reconhece mais facilmente no sonho nocturno também ocorre permanentemente no estado de vigília.

$\mathrm{Na}$ análise em grupo foi este processo que permitiu aceder às dimensões inconscientes dos significados dos conteúdos da entrevista. Assim, num segundo momento de análise, o grupo pôde reconhecer este processo, nomeá-lo, figurá-lo e representá-lo como momento defensivo face aos conteúdos da entrevista e, assim, começar a compreendêlo. Um facto selecionado emergiu: a inquietação provocada pela contratransferência erótica que é nomeada, mas imediatamente silenciada.

\subsection{Facto Selecionado}

$\mathrm{Na}$ análise da entrevista, o grupo experienciou a existência de elementos incoerentes, numa disposição particular para a escuta em capacidade negativa, ou seja, capaz de tolerar essa incoerência. Este processo permitiu a formação de imagens através do trabalho de sonho alfa, donde emergiu um facto seleccionado, isto é, uma experiência emocional de descoberta de uma coerência que permitiu passar de uma posição de dispersão, confusão, incompreensão para uma posição de integração e compreensão em direção ao conhecimento (Bion, 1962).

Bion recorre ao conceito de facto seleccionado de Poincaré para explicar o processo de produção de conhecimento. Diz Poincaré: "Si un résultat nouveau a du prix, c'est quand en reliant des éléments connus depuis longtemps, mais jusque-là épars et paraissant étrangers les uns aux autres, il introduit subitement l'ordre là où régnait l'apparence du désordre" (1908, p.25). Produto possível do trabalho de sonho alfa, a emergência de um facto seleccionado é determinante na cadeia de eventos que liga a indução a um sistema científico dedutivo; uma generalização que permite a criação de deduções.

A emergência da temática da sexualidade mobilizou nos investigadores - como na psicanalista entrevistada - o recurso a estratégias defensivas que inibiram 0 desenvolvimento do tema. No decurso da entrevista, como no momento da sua análise, os elementos eróticos associados à contratransferência foram silenciados por omissão ou pelo recurso à intelectualização.

\section{Conclusões}

Neste artigo, procurámos destacar a pertinência do uso de uma metodologia psicanaliticamente informada, partindo do pressuposto de um sujeito de investigação dividido e defendido, conflitual e "não transparente", bem como, ilustrar esta aplicação e sustentá-la com base na teoria do pensamento de Bion (1959, 1962, 1970). 
Assim, foi usado um exemplo decorrente de uma investigação conceptual em curso sobre a contratransferência para ilustrar os procedimentos da análise das entrevistas em grupo e a mobilização dos processos inconscientes dos investigadores, próximo do que sucede no trabalho clínico dos psicanalistas.

Esta metodologia permite encontrar o inesperado, o imprevisível, o novo, quer através do procedimento de realização das entrevistas, quer através dos procedimentos de análise e compreensão das mesmas, no seio do grupo de investigadores. Por oposição ao escrutínio lógico, esta metodologia permite o acesso a dimensões subjectivas inconscientes dos participantes. O foco de investigação desloca-se de um campo de significação mais superficial, literal, manifesto, para um campo de significação de natureza inconsciente e por isso latente, velado.

No entanto, a aplicação do racional psicanalítico fora do setting clínico coloca, necessariamente, questões. Enquanto que no setting clínico a solicitação para o encontro parte do paciente e é norteada por uma intenção terapêutica, no contexto de investigação a solicitação parte do investigador e tem como objetivo a produção de conhecimento. Esta diferença altera as condições do encontro e, dessa forma, desde logo, o que emerge na entrevista é, consciente e inconscientemente, influenciado por esses fatores. Dada a especificidade do método, coloca-se também a questão de existir, ou não, a necessidade de, no grupo de investigação, alguns ou todos os investigadores possuírem formação $e$ treino analítico. Poderá este racional ser usado por grupos de investigação apenas com conhecimento teórico da psicanálise, mas sem experiência do seu uso clínico? Finalmente, no setting clínico, uma hipótese interpretativa enunciada pelo analista em sessão mobiliza uma resposta associativa do paciente, na própria sessão ou em fases posteriores do processo terapêutico, que permitirá averiguar da sua maior ou menor adequação. No contexto de investigação temos um único encontro entre investigador e participante, onde não tem lugar a exploração interpretativa. Esta é realizada apenas posteriormente, no seio do grupo de investigadores. A averiguação da adequação da linha interpretativa tem, assim, de recorrer a formas de validação cruzadas. Por um lado, é realizada através da intersecção de olhares, sensibilidades, subjetividades e reflexões dos diferentes membros do grupo. Por outro, o cruzamento da compreensão da dinâmica grupal com as notas de campo reflexivas do entrevistador permite, também, observar convergências e/ou divergências que possibilitam aprofundar a compreensão do conteúdo das entrevistas. Finalmente, a este propósito, Hollway (comunicação pessoal, 24 Setembro, 2011) e Holmes (2019) observaram que diferentes grupos de discussão/investigação expostos à mesma transcrição tendem a produzir linhas interpretativas semelhantes.

Concluindo, a explicitação aqui exposta sobre o uso de uma metodologia qualitativa psicanaliticamente informada procurou sistematizar o uso da subjetividade do investigador como forma de expandir o campo da investigação qualitativa.

\section{Referências}

Bion, W. R. (1959). Attacks on linking. International Journal of Psycho-Analysis, 40, 308-315.

Bion, W. R. (1962). Learning from experience. Karnac Books.

Bion, W. R. (1970). Attention and interpretation: A scientific approach to insight in psycho-analysis and groups. Tavistock Publications.

Cartwright, D. (2004). The psychoanalytic research interview: Preliminary suggestions. Journal of the American Psychoanalytic Association, 52(1), 209-242

Dreher, A. U. (2000). Foundations for conceptual research in psychoanalysis. Karnac Books.

Freud, S. (1953). The interpretation of dreams. In J. Strachey (Ed.), The Standard Edition of the Complete Works of Sigmund Freud (Vol. 4, 5). The Hogarth Press Ltd. and the Institute of Psycho-Analysis. (obra original publicada em 1900)

Freud, S. (1961). The future prospects of psychoanalytic therapy. In J. Strachey (Ed.), The Standard Edition of the Complete Psychological Works of Sigmund Freud (Vol. 12) (pp. 139- 
152). The Hogarth Press Ltd. and the Institute of Psycho-Analysis. (obra original publicada em 1910)

Freud, S. (1963). Introductory lectures on psycho-analysis. In J. Strachey (Ed.), The Standard Edition of the Complete Psychological Works of Sigmund Freud (Vol. XVI). The Hogarth Press Ltd. and the Institute of Psycho-Analysis. (obra original publicada em 1916)

Frosh, S., \& Young, L. S. (2008). Psychoanalytic approaches to qualitative psychology. In C. Willig \& W. Stainton-Rogers (Eds.), The SAGE handbook of qualitative research in psychology (pp. 109-126). Sage. doi: 10.4135/9781848607927.n7

Stamenova, K., \& Hinshelwood, R. D. (Eds.). (2018). Methods of research into the unconscious: Applying psychoanalytic ideas to social science. Routledge.

Holmes, J. (2019). A practical psychoanalytic guide to reflexive research: The reverie research method. Routledge.

Hollway, W. (2004). An appropriate research paradigm for evaluating psychoanalytically-informed practices. International Journal of Infant Observation and its Applications, 7(2/3), 26-42.

Hollway, W. (2008). The Importance of relational thinking in the practice of psycho-social research: Ontology, epistemology, methodology and ethics. In S. Clarke, H. Hahn, \& P. Hoggett (Eds.), Object relations and social relations: The implications of the relational turn in psychoanalysis (pp. 137-162). Karnac Books.

Hollway, W. (2016). Emotional experience plus reflection: countertransference and reflexivity in research.The Psychotherapist, 62, 19-21.

Hollway, W., \& Jefferson, T. (2008). The free association narrative interview method. In L. Given (Ed.), The SAGE encyclopedia of qualitative research methods (pp. 296-315). Sage.

Hollway, W., \& Jefferson, T. (2013). Doing qualitative research differently: Free association, narrative and the interview method (2nd ed.). Sage. doi: 10.4135/9781526402233

Hollway, W., \& Froggett, L. (2012). Researching in-between subjective experience and reality. Forum: Qualitative Social Research, 13(3), Art. 13. doi: http://dx.doi.org/10.17169/fqs13.3.1899

Kvale, S. (2003). The psychoanalytical interview as inspiration for qualitative research. In P. M. Camic, J. E. Rhodes, \& L. Yardley (Eds.), Qualitative research in psychology: Expanding perspectives in methodology and design (pp. 275-297). American Psychological Association.

Laplanche, J., \& Pontalis, J. B. (1967). Vocabulaire de la psychanalyse. PUF.

Poincaré, H. (1908). Science et méthode. Flammarion.

Sandler, J., Dreher, A., \& Drews, S. (1991). An approach to conceptual research in psychoanalysis illustrated by a consideration of psychic trauma. International Review of Psycho-Analysis, 18, 133-141. 